Article

\title{
Exploring the Changing Gap of Residential Energy Consumption per Capita in China and the Netherlands: A Comparative Analysis of Driving Forces
}

\author{
Hongguang Nie ${ }^{1, * \mathbb{C}}$, René Kemp ${ }^{2,3}$ and Véronique Vasseur ${ }^{2}$ \\ 1 School of Economics and Management, Changchun University of Science and Technology, \\ Changchun 130022, China \\ 2 Maastricht Sustainability Institute, Maastricht University, 6200 MD Maastricht, The Netherlands; \\ r.kemp@maastrichtuniversity.nl (R.K.); veronique.vasseur@maastrichtuniversity.nl (V.V.) \\ 3 UNU-MERIT, Maastricht University, 6211 AX Maastricht, The Netherlands \\ * Correspondence: nhguang@126.com; Tel.: +86-4318-558-3372
}

Received: 19 May 2020; Accepted: 3 June 2020; Published: 5 June 2020

\begin{abstract}
This paper brings out some remarkable differences between China as a developing country experiencing high economic growth and the Netherlands as a developed country by examining the driving forces behind the evolution of residential energy consumption per capita (RECpc) in the two countries in the period from 2001 to 2015 . The components we analysed are income, energy-intensity, weather and energy-mix effects. The most remarkable result is the changing effect of energy intensity in China: during 2001-2007 energy intensity increased, and decreased afterward. The changes reflected changes in material circumstances: the shift to relative energy intensive goods and of saturation of energy demand for heating and cooling. In the Netherlands, the declining energy intensity, warmer winters and the more diversified energy mix decreased RECpc by 511.39, 58.81 and $1.08 \mathrm{kgce}$, respectively. Although the income growth both increased RECpc in the two countries, the relatively high-speed increasing income in China narrowed the RECpc gap between the two countries. This study implies that the opposite changes in RECpc in developing and developed countries are due to the different development stages reached by the countries. Policy suggestions are being offered to deal with the different circumstances, as revealed through this study.
\end{abstract}

Keywords: changing gap of residential energy consumption; energy intensity; weather effect; economic development stages; cross-country comparison

\section{Introduction}

Despite the wide gap in per capita energy consumption between developed and developing countries, it has somewhat narrowed over recent decades. Figure 1 describes the energy consumption per capita in Organisation for Economic Co-operation and Development (OECD) countries and non-OECD countries; it shows that although the increase in energy consumption per capita in developing countries and the respective decrease in developed countries have led to a narrower per capita energy consumption gap, the gap remains wide, especially in the residential sector [1].

To investigate the reasons behind the large gap in residential energy consumption (REC) between developing and developed countries, we select China and the Netherlands, respectively, as typical examples. As shown in Table 1, although China and the Netherlands differ greatly in terms of land area and population, we compare their residential energy consumption per capita (RECPc), which is not affected by the size of the two countries. As a typical developed country, as well as an OECD 
country, the Netherlands' GDP per capita is more than five times that of China as a typical developing country (non-OECD country). Therefore, the analysis of RECpc in the Netherlands can be a valuable reference for the study of China's RECpc in the future. Dutch RECpc decreased from 15.8 million TCE to 13.3 million TCE, a 15.6\% decline over the period 2001-2015 (Central Agency for Statistics, CBS, 2017a), indicating a state of saturation, which can be regarded as the growth potential of China's RECpc. Through further comparison of the decomposition results in China and the Netherlands, it is easy to understand what the role of the driving force behind RECpc growth will be after China's RECpc is saturated. More importantly, as shown in Figure 1, the trends of residential energy consumption per capita (RECpc) in China and the Netherlands are highly consistent with those of RECpc in developing and developed countries, respectively, supporting the selection of both nations as typical examples. In addition, this study is the result of a Sino-Dutch international cooperation project, "Energy Efficiency of Households in Cities: A Multi-method Analysis", which aims to compare the characteristics of China and the Netherlands' residential energy consumption, and to provide references for future residential energy policies for both sides. The cooperation has provided us with an opportunity to gain an in-depth understanding of the REC characteristics on both sides. In China, as a developing country with sustained and rapid economic growth, REC has increased dramatically over the past decade, from 114.5 million tons of coal equivalent (TCE) to 339.9 million TCE, a 1.97-fold growth over the 2001-2015 period (DESNBS, 2016). In contrast, in the Netherlands, as a developed country in Europe, REC decreased from 15.8 million TCE to 13.3 million TCE, a $15.6 \%$ decline over the same period [2]. However, China's RECpc lags far behind that of The Netherlands.

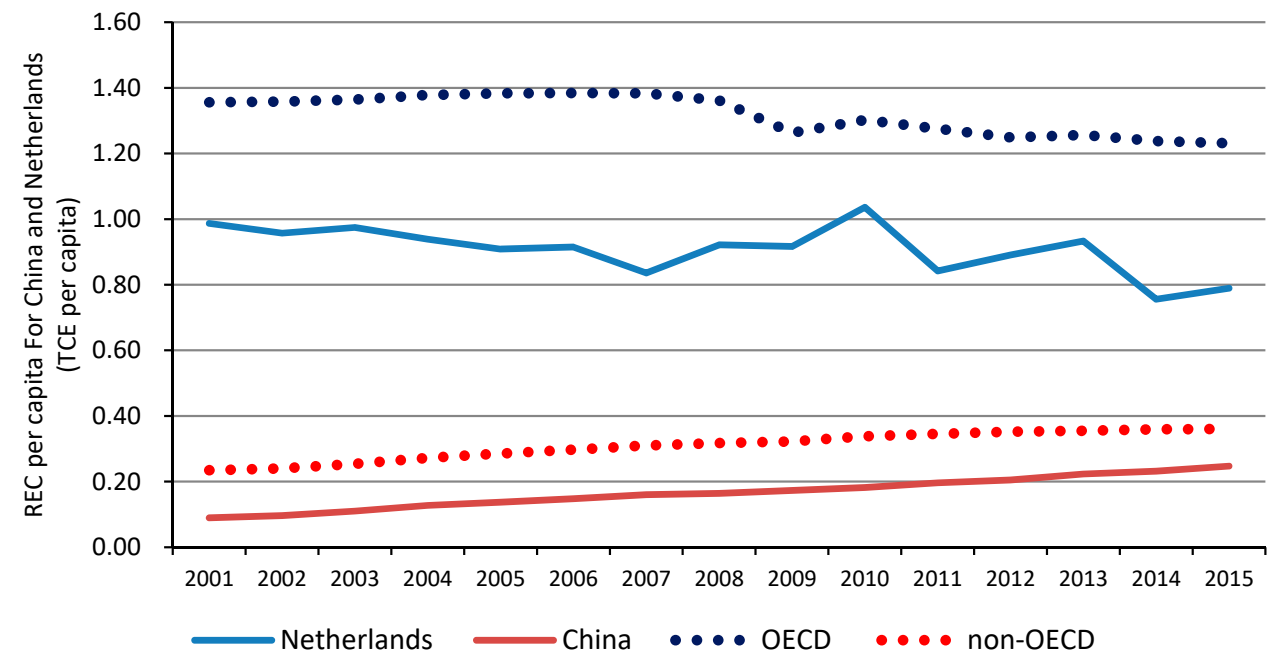

Figure 1. REC per capita in the Netherlands, China, and REC per capita in OECD and non-OECD. Data sources: China Statistical Yearbooks and China Energy Statistical Yearbooks (2001-2016); Central Agency for Statistics (2017); BP Statistical Review of World Energy (2016); Swan and Ugursal (2009) and authors' calculations.

Table 1. Comparison of the basic situation between China and the Netherlands.

\begin{tabular}{ccc}
\hline Country & China & The Netherlands \\
\hline OECD or not & Non-OECD & OECD \\
Area & 9.63 million km ${ }^{2}$ & 41.53 thousand $\mathrm{km}^{2}$ \\
Population & 1.40 billion & 17.26 million \\
GDP per capita & 9909 Dollars & 52978 Dollars \\
Main housing type & Apartment & House \\
Most important residential energy types & Electricity, Coal & Natural gas, Electricity \\
Heating degree days & 2162 & 2595 \\
\hline
\end{tabular}

Data sources: China Statistical Yearbook and China Energy Statistical Yearbook (2016); Central Agency for Statistics (2017). 
In this study, we analyze the RECpc changes in China and the Netherlands over the 2001-2015 period, using the logarithmic mean Divisia index (LMDI) method. The weather effect is included due to its significant influence on REC, which was analyzed in the study of [3]. In our research, we decompose the changes into four effects: weather, energy mix, energy intensity and income, to investigate the driving forces behind the RECpc changes in the two countries. Furthermore, we conduct a cross-country comparison of these driving forces over the same period to examine the reasons for the opposite changing directions in both countries. Policies for developing and developed countries are proposed based on the analysis results.

This paper is structured as follows. Section 2 reviews the literature on REC in developed and developing countries, using the decomposition analysis method. Section 3 presents the methodology and the data sources. The results for both countries are provided and discussed in Section 4, followed by the cross-country comparison in Section 5 . Section 6 summarizes the findings and the conclusions and proposes energy policies for developing and developed countries based on their individual characteristics of RECpc.

\section{Literature Overview}

Various scholars have investigated the driving factors behind REC changes, not only in developed countries but also in developing countries [4-6]. Starting with some remarkable results from developed countries, Shorrock found that carbon emissions in the UK declined over the 1990-2000 period, and further analyzed the driving forces behind the change [7]. According to the cited study, carbon emissions in the UK decreased by $5.32 \mathrm{MtC}$ due to improved insulation and efficiency, as well as fuel switching to natural gas. In contrast, increased numbers of households, improved levels of service and changes in external temperatures slowed down the decline of carbon emissions. Greening et al. conducted a comparison analysis of carbon emissions from the residential sector in 10 OECD countries over the 1970-1993 period and further investigated the effects of changes in residential per capita carbon emissions [8]. According to the results, per capita carbon emissions declined in six OECD countries, including Denmark, France, Norway, Sweden, the UK and the USA. In four other OECD countries (Finland, Germany, Italy and Japan), per capita carbon emissions increased over the research period but on a small scale. Various effects drove the changes in per capita carbon emissions; changes in energy intensity and in primary fuel mix for electricity generation were the two largest effects that contributed to restraining the carbon emissions. Unander et al. examined REC in Denmark, Norway and Sweden over the 1973-1999 period. Their study showed a decline in REC in Denmark and Sweden [9]. Although REC increased in Norway over the investigated period, since 1990 it had come to a halt. In analyzing the driving forces behind the REC changes in the three countries, the decline in energy intensity and per capita energy use could explain most of the REC decreases, whereas the structure effect played the opposite role. Hojjati and Wade investigated the driving forces behind REC changes in the USA over the 1980-2005 period [5]. In their study, REC changes in the USA were decomposed into six effects, including housing, region, type, square foot per household, intensity and weather effects. Over the period under study, REC in the USA increased by $12.4 \%$ on a small scale due to changes in the housing type and in living space improvements. Rogan et al. conducted a decomposition analysis of gas consumption in Ireland's residential sector and examined the impacts of gas consumption changes over the 1990-2008 period. According to their study, gas consumption kept increasing until 2004; however, it started to decline afterwards. They found that increases in customer numbers and gas consumption per dwelling were the main driving forces behind the gas consumption increase. The subsequent decline could be attributed to the decrease in gas consumption per dwelling despite the continued increase in the number of customers [10].

The driving factors behind REC in developing countries have also been investigated recently $[4,11,12]$. Achão and Schaeffer examined the driving forces behind REC in Brazil over the 1980-2007 period, which increased from 23.3 to $90.2 \mathrm{TWh}$, with an annual growth rate of $5.2 \%$ [4]. The share of REC in the total electricity consumption increased by $3 \%$, from $19 \%$ in 1980 to $22 \%$ in 2007 . The results showed that 
the increase in the number of consumers and in electricity consumption per capita contributed most to the electricity consumption increase in Brazil. Das and Paul found that $\mathrm{CO}_{2}$ emissions from household consumption, accounting for $12 \%$ of total $\mathrm{CO}_{2}$ emissions, increased by $66 \%$ in India between 1993-1994 and 2006-2007. Among the driving forces, the increase in expenditure per capita and population, as well as the expenditure structure shift, positively contributed to the increase in $\mathrm{CO}_{2}$ emissions. Meanwhile, energy intensity was the only effect that played the opposite role in the increase in $\mathrm{CO}_{2}$ emissions [11]. In recent years, related studies on China have increasingly been undertaken [13-15]. Zha et al. investigated the driving factors behind the increase in residential $\mathrm{CO}_{2}$ emissions in China's urban and rural areas over the 1991-2004 period. The income effect increased residential $\mathrm{CO}_{2}$ emissions in both urban and rural areas, whereas energy intensity played the opposite roles over the same period [13]. Zhao et al. decomposed REC in urban China into various effects, including price, structure, expenditure and population, over the 1998-2007 period. Their study showed an obvious increase in REC in urban China [16]. Furthermore, the increase in the population, expenditure and energy-cost share in the total expenditure led to the REC increase, whereas the energy price reform and the energy-mix shift to cleaner and more comfortable forms restrained the REC increase. Nie and Kemp found a 101\% increase in REC in China over the 2002-2010 period and investigated the underlying driving forces. According to the results, the increases in energy consumption per square meter and floor space per capita were the two main driving forces. The population growth also contributed to the REC increase in China [17]. Liu and Zhao measured the driving factors behind REC in China over the 1993-2011 period and found a dramatic increase in REC. By decomposing REC into various driving factors, they found that the increases in income and in the energy-cost share contributed most to the REC increase, whereas the rise in energy prices was the sole factor that restrained the REC increase [18]. Nie et al. analyzed the reasons for the REC increase in urban and rural China and further measured the weather effect on the REC change. Their study pointed out the distinction between urban and rural REC and emphasized the effects of income and weather on the REC change in both urban and rural areas [3].

Based on the aforementioned studies, we can conclude that REC declined in most of the developed countries and it increased in all developing countries. In developed countries, the improvements in energy efficiency caused a decrease in REC, whereas improvement in living conditions played the opposite role. Because energy efficiency improved more significantly than living conditions, REC declined in the majority of the developed countries. In contrast, in developing countries, given the low level of energy infrastructure development in the wake of the rapid economic progress, income grew significantly with economic growth, which was the main driving force behind the REC increase. Although the improvement in energy efficiency restrained the REC increase, the effect was limited, so it could not possibly change the REC shifting trend.

It is interesting to investigate the driving forces behind the REC changes in both developed and developing countries and further compare these driving forces in different nations. To our best knowledge, such studies are rare. Additionally, as an important determinant of REC, the weather effect has not been investigated in most of the previous studies, based on the framework of index decomposition analysis, especially in China and the Netherlands.

\section{Methodology and Data Sources}

In this paper, we decompose the factors influencing RECpc in China and the Netherlands, using the LMDI method, and analyze the specific characteristics of RECpc from 2001 to 2015. The research period spans from China's "tenth five-year plan" to the "twelfth five-year plan". After entering the "thirteenth five-year plan", economic transformation and industrial restructuring policies have both had a significant impact on China's economy and energy consumption, which would definitely influence our results. In order to minimize the impact of phased policies, our research deadline is the twelfth five-year plan. We decompose the RECpc changes into four driving forces simultaneously, comprising weather, energy-mix, energy-intensity and income effects. In this section, we present the methods of decomposition, the measurement for the weather effect and the data description. 


\subsection{Logarithmic Mean Divisia Index Method}

The LMDI method has several advantages over other index decomposition analysis methods. First, the LMDI decomposition is more scientific because it satisfies the factor-reversal test by using the additive property of log percent $[19,20]$. Second, the LMDI offers perfect decomposition results with no residuals $[10,19]$. Third, next to having a stronger theoretical foundation, the results from the additive form of the LMDI are given in physical units, which are easier to interpret relative to indexes in a multiplicative case [21,22]. Thus, the LMDI model is selected to analyze the RECpc changes in both China and the Netherlands.

The annual aggregate REC in China or the Netherlands can be disaggregated into five parts, as follows:

$$
\operatorname{REC}_{i}=\sum_{j} \frac{\check{E}_{i j}}{E_{i j}} \times \frac{E_{i j}}{E_{i}} \times \frac{E_{i}}{I_{i}} \times \frac{I_{i}}{P_{i}} \times P_{i}
$$

where REC $_{\mathbf{i}}$ signifies the REC in country $\mathbf{i} ; \check{\mathbf{E}_{i j}}$ refers to the REC in country $\mathbf{i}$ and to energy type $\mathbf{j}$ affected by weather; $\mathbf{E}_{\mathbf{i j}}$ denotes the REC in country $\mathbf{i}$ and energy type $\mathbf{j}$; $\mathbf{E}_{\mathbf{i}}$ means the total REC consumption in country $\mathbf{i} ; \mathbf{I}_{\mathbf{i}}$ represents the income in country $\mathbf{i}$, and $\mathbf{P}_{\mathbf{i}}$ indicates the population in country $\mathbf{i}$.

Both sides of the equation are divided by $\mathbf{P}_{\mathbf{i}}$ at the same time, as shown in the follow equation:

$$
\frac{R C_{i}}{P_{i}}=R E C p c_{i}=\sum_{j} \frac{\check{E_{i j}}}{E_{i j}} \times \frac{E_{i j}}{E_{i}} \times \frac{E_{i}}{I_{i}} \times \frac{I_{i}}{P_{i}}
$$

We further express each factor in Equation (2), as follows:

$\mathbf{R E C P c}_{\mathbf{i}}=\frac{\mathbf{R E C}_{\mathbf{i}}}{\mathbf{P}_{\mathbf{i}}}$ represents the RECpc in country $\mathbf{i}$;

$\omega_{i j}=\frac{E_{i j}}{E_{i j}}$ refers to the weather-adjusted coefficient in country $i$, representing the weather effect;

$\mathbf{E M}_{\mathrm{ij}}=\frac{\mathrm{E}_{\mathrm{ij}}}{\mathrm{E}_{\mathrm{i}}}$ indicates the energy-mix effect, referring to the percentage of each energy type $\mathbf{j}$ in the total REC in country $\mathbf{i}$;

$\mathbf{E I}_{\mathbf{i}}=\frac{\mathbf{E}_{\mathbf{i}}}{\mathbf{I}_{\mathbf{i}}}$ denotes the energy-intensity effect, referring to the ratio of the REC to the total income in country $\mathbf{i}$;

$\mathbf{I E}_{\mathbf{i}}=\frac{\mathbf{I}_{\mathbf{i}}}{\mathbf{P}_{\mathbf{i}}}$ signifies the income effect, referring to the income per capita in country $\mathbf{i}$.

Thus, the decomposition equation could be expressed as follows:

$$
\mathrm{RECPc}_{\mathbf{i}}=\sum_{\mathbf{j}} \omega_{\mathrm{ij}} \times \mathrm{EM}_{\mathrm{ij}} \times \mathrm{EI}_{\mathbf{i}} \times \mathrm{IE}_{\mathbf{i}}
$$

Following Ang's study [23], the RECpc changes in both China and the Netherlands could be further decomposed as follows:

$$
\begin{aligned}
& \triangle \mathbf{R E C P c}_{\mathbf{i}}=\mathbf{R E C P c}_{\mathbf{i}}^{\mathrm{t}}-\mathbf{R E C P c}_{\mathrm{i}}^{\mathrm{t}-1} \\
& =\Delta \mathbf{R E C p c}_{\mathrm{we}}+\Delta \mathrm{RECpc}_{\mathrm{em}}+\Delta \mathrm{RECpc}_{\mathrm{ei}}+\Delta \mathrm{RECpc}_{\mathrm{ie}} \\
& \Delta \operatorname{RECPc}_{w e}=\sum_{j} \frac{v_{i j}^{t}-v_{i j}^{t-1}}{\ln v_{i j}^{t}-\ln v_{i j}^{t-1}} \ln \left(\frac{\omega_{i j}^{t}}{\omega_{i j}^{t-1}}\right) \\
& \Delta \text { RECPc }_{e m}=\sum_{j} \frac{v_{i j}^{t}-v_{i j}^{t-1}}{\ln v_{i j}^{t}-\ln v_{i j}^{t-1}} \ln \left(\frac{E M_{i j}^{t}}{E M_{i j}^{t-1}}\right)
\end{aligned}
$$




$$
\begin{aligned}
\triangle \text { RECPc }_{e i} & =\sum_{j} \frac{v_{i j}^{t}-v_{i j}^{t-1}}{\ln v_{i j}^{t}-\ln v_{i j}^{t-1}} \ln \left(\frac{E_{i}{ }^{t}}{E I_{i}^{t}-1}\right) \\
\triangle R E C p c_{i e} & =\sum_{j} \frac{v_{i j}^{t}-v_{i j}^{t-1}}{\ln v_{i j}^{t}-\ln v_{i j}^{t-1}} \ln \left(\frac{I E_{i}^{t}}{I E_{i}{ }^{t}-1}\right)
\end{aligned}
$$

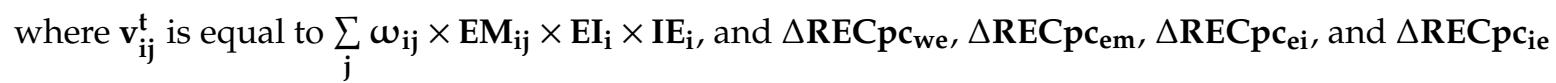
indicate RECpc changes in both China and the Netherlands due to weather, energy-mix, energy-intensity and income effects, respectively.

Additionally, the subscripts $\mathbf{i}, \mathbf{j}$ and $\mathbf{t}$ represent the two countries (China and the Netherlands), energy types and years, respectively.

\subsection{Methodology for Measuring Weather Effect}

Since space heating and cooling activities are directly determined by heating and cooling degree days in the residential sector, the degree days could be used to represent REC for space heating and cooling. We further use the degree days in year $t$ divided by the mean of degree days over the research period to represent the weather change effect in year $\mathbf{t}$, which is defined as a weather-adjusted coefficient. The weather-adjusted coefficient is shown in the following equation:

$$
\omega_{i j}^{t}=\frac{\check{E_{i j}}}{E_{i j}^{t}}=\frac{(\text { HDD }+C D D)^{t}}{(H D D+C D D)^{a v e}}
$$

where HDD represents heating degree days; CDD means cooling degree days. $(\text { HDD }+ \text { CDD })^{\mathbf{t}}$ denotes the sum of HDD and CDD corresponding to the REC for space heating and cooling in year $\mathbf{t}$, representing the weather change influence in year $\mathbf{t}$. $(\text { HDD }+\mathbf{C D D})^{\text {ave }}$ indicates the mean of the sum of HDD and CDD over the research period, corresponding to the REC for space heating and cooling, assuming it to be unaffected by weather change, which shows as reasonable.

Thus, the ratio of $(\text { HDD }+\mathbf{C D D})^{\mathbf{t}}$ and $(\text { HDD }+\mathbf{C D D})^{\text {ave }}$ represents the REC determined by the weather change in year $\mathbf{t}$ relative to REC without the weather change influence. Here, it is necessary to indicate that using the sum of HDD and CDD to represent the weather effect is a common, reasonable method [5,24]. Additionally, because HDD corresponds to the REC for space heating, and CDD corresponds to the REC for space cooling, even though HDD and CDD correspond to different types of energy in some cases, the sum of HDD and CDD corresponds to the REC for space heating and cooling, owing to the weather.

\subsection{Data Sources and Calculation}

We collected the raw data for this study from multiple statistical yearbooks. The income, population and temperature data for China came from the China Statistical Yearbooks (CSYs) [25]. We gathered the energy consumption data for China from the China Energy Statistical Yearbooks (CESYs) $[26,27]$. The raw data for the Netherlands were collected from the CBS $[2,28,29]$ and the Royal Netherlands Meteorological Institute [30]. For making comparisons of income between China and the Netherlands which use different currencies, it is necessary to convert values to a common currency. This can be done in two ways by using market exchange rates and purchasing power parities (PPPs). There are some difficulties in using market exchange rates due to the following weaknesses. First, the market exchange rates change quickly sometimes, which will artificially lead to changes of income in the analysis. Second, the market exchange rates are determined by supply and demand of currencies on the international market, which is not determined on a consistent basis. In this study, we use PPPs to convert Chinese yuan and Dutch euro into US Dollar [31]. The PPPs are calculated based on the quantity of the currency needed to purchase a given basket of goods and services [32]. Therefore, PPPs 
are used for equalizing the purchasing power of two currencies by taking into account these cost of living and inflation differences, which not only make currencies in the two countries comparable, but also eliminate the influence of inflation.

As a result of the Netherlands' relatively small land area, the temperature degrees in different parts of the country varied negligibly. Thus, we used the monthly average temperature in the Netherlands to calculate HDD and CDD in the country. Based on the report of the Asia-Pacific Energy Research Centre [33], when the outdoor temperature is below $18^{\circ} \mathrm{C}$, the indoor temperature needs to be raised to $18^{\circ} \mathrm{C}$ by heating. In the same way, when the outdoor temperature is higher than $26^{\circ} \mathrm{C}$, it is necessary to cool the indoor temperature to $26^{\circ} \mathrm{C}$. Consistent with some previous studies [24,33,34], we use $18^{\circ} \mathrm{C}$ and $26^{\circ} \mathrm{C}$ as the criteria for calculating HDDS and CDD. We note that various criteria are used in calculating degree days in different countries; however, for the sake of comparison, we uniformly adopt the Chinese criteria here. The HDD and the CDD in the Netherlands are calculated as follows: $\mathbf{H D D}_{\mathbf{t o t}}^{\mathrm{t}, \mathbf{D}}=\sum_{\mathbf{p}=1}^{\mathbf{m}} \operatorname{HDD}_{\mathbf{p}}^{\mathrm{t}, \mathbf{D}}(\mathrm{m}=12)$, and

$$
\mathbf{H D D}_{\mathbf{p}}^{\mathbf{t}, \mathbf{D}}=\left\{\begin{array}{lcc}
\left(18-\mathbf{T}_{\mathbf{p}}\right) \times \mathbf{d}_{\mathbf{p}} & \text { if } & \mathbf{T}_{\mathbf{p}}<18 \\
0 & \text { if } & \mathbf{T}_{\mathbf{p}} \geq 18
\end{array}\right.
$$

$$
\operatorname{CDD}_{\text {tot }}^{\mathbf{t}, \mathbf{D}}=\sum_{\mathbf{p}=1}^{\mathbf{m}} \operatorname{CDD}_{\mathbf{p}}^{\mathbf{t}, \mathbf{D}}(\mathrm{m}=12) \text {, and }
$$

$$
\operatorname{CDD}_{\mathbf{p}}^{\mathbf{t}, \mathbf{D}}=\left\{\begin{array}{lcc}
\left(\mathbf{T}_{\mathbf{p}}-26\right) \times \mathbf{d}_{\mathbf{p}} & \text { if } & \mathbf{T}_{\mathbf{p q}}>26 \\
0 & \text { if } & \mathbf{T}_{\mathbf{p q}} \leq 26
\end{array},\right.
$$

where HDD $_{\text {tot }}^{\mathbf{t}, \mathbf{D}}$ and $\mathbf{C D D}_{\text {tot }}^{\mathbf{t}, \mathbf{D}}$ refer to the total HDD in year $\mathbf{t}$ and the total CDD in year $\mathbf{t}$, respectively; $\mathbf{H D D}_{\mathbf{p}}^{\mathbf{t}, \mathbf{D}}$ and $\mathbf{C D D}_{\mathbf{p}}^{\mathbf{t}, \mathbf{D}}$ indicate the HDD in month $\mathbf{p}$ of year $\mathbf{t}$ and the CDD in month $\mathbf{p}$ of year $\mathbf{t}$, respectively; $\mathbf{T}_{\mathbf{p}}$ denotes the average temperature in month $\mathbf{p} ; \mathbf{d}_{\mathbf{p}}$ signifies the number of days of month $\mathbf{p}$ and $\mathbf{m}$ represents the number of months (12) in one year.

On the other hand, due to China's enormous size, it is inaccurate to calculate HDD and CDD by using the average temperature in the country. China's temperature changes a lot during the different seasons and in various regions; therefore, regional variations across the nation and the seasons must be taken into account. To overcome these problems, we picked 31 cities in 31 provinces and then calculated the HDD and the CDD in these cities. The annual HDD and CDD in China over the 2001-2015 period comprise the sum of the HDD and the CDD in the 31 cities. Due to the limited availability of temperature data, we use the monthly temperature data in these cities to calculate their annual HDD and CDD, as follows:

$$
\begin{array}{r}
\mathbf{H D D}_{\mathbf{t o t}}^{\mathbf{t}, \mathrm{C}}=\sum_{\mathbf{q}=1}^{\mathbf{n}} \sum_{\mathbf{p}=1}^{\mathbf{m}} \mathbf{H D D}_{\mathbf{p q}}^{\mathrm{t}, \mathrm{C}}(\mathrm{m}=12, \mathrm{n}=31), \text { and } \\
\mathbf{H D D}_{\mathbf{p q}}^{\mathbf{t}, \mathbf{C}}=\left\{\begin{array}{cc}
\left(18-\mathbf{T}_{\mathbf{p q}}\right) \times \mathbf{d}_{\mathbf{p}} & \text { if } \mathbf{T}_{\mathbf{p q}}<18 \\
0 & \text { if } \mathbf{T}_{\mathbf{p q}} \geq 18
\end{array}\right. \\
\mathbf{C D D}_{\mathbf{t o t}}^{\mathbf{t}, \mathbf{C}}=\sum_{\mathbf{q}=1}^{\mathbf{n}} \sum_{\mathbf{p}=1}^{\mathbf{m}} \mathbf{C D D}_{\mathbf{p q}}^{\mathbf{t}, \mathbf{C}}(\mathrm{m}=12, \mathrm{n}=31), \text { and } \\
\mathbf{C D D}_{\mathbf{p q}}^{\mathbf{t}, \mathbf{C}}=\left\{\begin{array}{ll}
\left(\mathbf{T}_{\mathbf{p q}}-26\right) \times \mathbf{d}_{\mathbf{p}} & \text { if } \mathbf{T}_{\mathbf{p q}}>26 \\
0 & \text { if } \mathbf{T}_{\mathbf{p q}} \leq 26
\end{array},\right.
\end{array}
$$

where $\mathbf{H D D}_{\text {tot }}^{\mathbf{t}, \mathbf{C}}$ and $\mathbf{C D D}_{\text {tot }}^{\mathbf{t}, \mathbf{C}}$ signify the total HDD in year $\mathbf{t}$ and the total CDD in year $\mathbf{t}$ in China, respectively; $\mathbf{H D D}_{\mathbf{p q}}^{\mathbf{t}, \mathbf{C}}$ and $\mathbf{C D D}_{\mathbf{p q}}^{\mathbf{t}, \mathbf{C}}$ indicate the HDD in month $\mathbf{p}$ of year $\mathbf{t}$ in city $\mathbf{q}$ and the CDD in month $\mathbf{p}$ of year $\mathbf{t}$ in city $\mathbf{q}$ in China, respectively; $\mathbf{T}_{\mathbf{p q}}$ denotes the average temperature in month $\mathbf{p}$ in city $\mathbf{q} ; \mathbf{d}_{\mathbf{p}}$ refers to the number of days of month $\mathbf{p}$, and $m$ and $n$ represent the number of months (12) in one year and the number of cities (31), respectively. 


\section{Results and Analysis}

Based on the obtained data from China and the Netherlands, we decompose the RECpc changes in China and the Netherlands into four effects-weather, energy mix, energy intensity and income. Our study shows the following findings. Income is the key effect that increases RECpc both in China and the Netherlands. Meanwhile, the smaller energy intensity and milder weather decrease the RECpc in China and the Netherlands simultaneously. A more convenient and cleaner energy mix increases RECpc in China but a diversified energy mix decreases RECpc in the Netherlands by changing Dutch habits. In China, increased income plays a major role leading to an increase of RECpc. Conversely, the declined energy intensity contributes overwhelmingly, which causes RECpc to decrease in the Netherlands. In the following sub-sections, we present the detailed decomposition results in China and the Netherlands, respectively.

\subsection{Results of Decomposition of Changes in China's Residential Energy Consumption per Capita}

As shown in Table 2, from 2001 to 2015, RECpc spiked from 90 to 247 kgce per capita in China. Each row in Table 2 represents the decomposition result of RECpc change between two consecutive years. For example, the first row shows the change in RECpc from 2001 to 2002 and the contributions of various drivers. During this period, weather and energy-intensity effects decreased RECpc by 12.88 and $72.39 \mathrm{kgce}$, amounting to decreases of $8.17 \%$ and $45.93 \%$. Energy-mix and income effects increased RECpc by 0.07 and $242.81 \mathrm{kgce}$, representing increases of $0.05 \%$ and $154.05 \%$.

Table 2. Results of decomposition of changes of REC per capita in China in the unit of kgce.

\begin{tabular}{cccccc}
\hline Periods & Weather & Energy Mix & Energy Intensity & Income & RECpc Change \\
\hline $2001-2002$ & -6.286 & 0.001 & 1.710 & 10.794 & 6.218 \\
$2002-2003$ & 6.772 & 0.001 & -2.188 & 9.653 & 14.239 \\
$2003-2004$ & -7.447 & 0.008 & 14.961 & 9.790 & 17.312 \\
$2004-2005$ & 15.487 & 0.007 & -20.969 & 15.053 & 9.577 \\
$2005-2006$ & -12.400 & 0.006 & 6.274 & 16.490 & 10.370 \\
$2006-2007$ & -7.670 & 0.017 & 1.178 & 18.948 & 12.473 \\
$2007-2008$ & 11.665 & 0.002 & -22.658 & 14.980 & 3.989 \\
$2008-2009$ & 1.425 & 0.002 & -10.759 & 18.009 & 8.677 \\
$2009-2010$ & 6.718 & 0.007 & -10.924 & 13.576 & 9.377 \\
$2010-2011$ & 2.314 & 0.005 & -6.227 & 17.996 & 14.088 \\
$2011-2012$ & 5.166 & 0.003 & -22.107 & 25.764 & 8.826 \\
$2012-2013$ & -10.930 & 0.003 & 6.994 & 22.094 & 18.161 \\
$2013-2014$ & -13.756 & 0.002 & -2.553 & 25.039 & 8.732 \\
$2014-2015$ & -3.934 & 0.007 & -5.124 & 24.630 & 15.579 \\
Total & -12.876 & 0.072 & -72.392 & 242.814 & 157.618 \\
\hline
\end{tabular}

Data sources: CSY and CESY (2001-2016); CBS (2017a, 2017b, 2018) and KNMI; and authors' calculations.

The income effect overwhelmingly contributed to the RECpc increase, owing to China's continuous rapid growth in per capita income. Over the 2001-2015 period, China's per capita income increased from 1503 US dollars to 6491 US dollars, a threefold increase [25]. Because of the originally rather low level of income, its increasing potential in China was huge, leading to its continuous rapid growth over the research period. Notwithstanding the large increase in China's income per capita, in 2015 it was still much lower than those in developed countries; for example, the Netherlands' income per capita in 2015 comes down to 21,253 US dollars, still three times more than that in China.

The energy-mix effect also contributed to the RECpc increase but on a limited scale. Over the 2001-2015 period, the shares of coal, liquefied petroleum gas (LPG) and gas declined significantly; meanwhile, the shares of electricity and natural gas increased, indicating the shift to a cleaner and more convenient energy mix in China. The energy mix changed as a result of economic growth, urbanization and infrastructure development. Economic growth increased the usage of household appliances and vehicles, which leads to the increase of electricity and gasoline consumption. The use of coal and gas is 
reduced in the process of urbanization, and with the infrastructure development, natural gas is more and more popular in urban households.

Energy intensity had a changing effect on RECpc in China. The changing trend of energy intensity is upward, because previously people's REC demand had not been satisfied [35], and growing income allowed people to heat the homes more in winter or to cool their homes during hot days. After 2007, energy intensity had dropped, reflecting that the people's REC demand had been basically satisfied. Therefore, as a result of their increased income, they could spend more on items other than energy.

The weather effect was the second largest contributor to the RECpc decrease in China. The weather effect played different roles in the RECpc change over the various sub-periods of the research period. In detail, in 2001-2007, the weather effect increased RECpc for two years and decreased it for four years, but the total weather effect on RECpc change was rather limited over the cited sub-period. In contrast, in 2007-2012, the weather effect continued to promote RECpc increases, which could be explained by the emergence of abnormal weather circumstances, such as an extremely cold winter or extremely hot summer. However, since 2013, the weather effect had been declining. In total, as the second largest contributor, the weather effect decreased RECpc.

\subsection{Results of Decomposition of Changes in Dutch Residential Energy Consumption per Capita}

Over the 2001-2015 period, the Dutch RECpc decreased from 988 to 789 kgce per capita. Using the same decomposition model as the one applied in the study on China, we decompose the RECpc change in the Netherlands into four driving effects: weather, energy mix, energy intensity and income (Table 3).

Table 3. Results of decomposition of changes of REC per capita in the Netherlands in the unit of kgce.

\begin{tabular}{cccccc}
\hline Periods & Weather & Energy Mix & Energy Intensity & Income & RECpc Change \\
\hline $2001-2002$ & -55.020 & -0.002 & 14.259 & 9.395 & -31.368 \\
$2002-2003$ & 69.125 & 0.000 & -39.898 & -11.179 & 18.048 \\
$2003-2004$ & -12.267 & -0.001 & -77.951 & 52.434 & -37.785 \\
$2004-2005$ & -44.716 & -0.001 & -34.928 & 49.016 & -30.630 \\
$2005-2006$ & -27.118 & 0.000 & -69.598 & 102.792 & 6.076 \\
$2006-2007$ & -45.893 & -0.015 & -80.736 & 48.831 & -77.813 \\
$2007-2008$ & 77.259 & 0.015 & -59.438 & 69.832 & 87.667 \\
$2008-2009$ & 16.394 & 0.000 & 37.513 & -58.342 & -4.435 \\
$2009-2010$ & 175.061 & 0.032 & -76.458 & 20.442 & 119.078 \\
$2010-2011$ & -225.289 & -0.157 & 10.112 & 20.620 & -194.714 \\
$2011-2012$ & 71.163 & 0.002 & -46.142 & 22.304 & 47.327 \\
$2012-2013$ & 69.214 & 0.002 & -77.016 & 51.483 & 43.683 \\
$2013-2014$ & -210.589 & -0.958 & 34.823 & -0.498 & -177.222 \\
$2014-2015$ & 83.865 & 0.003 & -45.934 & -4.841 & 33.093 \\
Total & -58.811 & -1.080 & -511.391 & 372.287 & -198.995 \\
\hline
\end{tabular}

Data sources: CSY, CESY and PYC (2001-2016); CBS (2017a, 2017b, 2018) and KNMI, and authors' calculation.

Three of the four effects decreased RECpc, namely, energy intensity, weather and energy mix. The energy intensity effect contributed most to the decline in the Dutch RECpc due to the drop in energy intensity over the research period. In the 2001-2015 period, energy intensity in the Netherlands decreased from 0.68 to 0.39 TCE per 10,000 US dollars. Since the Dutch people's REC demand had already been satisfied for a long time, they did not need to spend more of their income on increasing their REC, which leads to a decline of energy intensity in the residential sector in the Netherlands, and the energy intensity is expected to further decline in the future.

The weather effect was the second largest contributor to the decline of the Dutch REC. Because of the cool weather in the summer, there was no CDD in the Netherlands over the research period; the weather effect was determined by HDD only. The weather influenced RECpc by changing energy 
for heating in the Netherlands, so the negative effect of the weather on the Dutch RECpc was due to the relatively warm weather during the winter period. Additionally, the total RECpc change from the weather effect was limited, which would have been easy to change due to the positive weather effect in the following year. Thus, we argue that no significant change in temperature occurred in the Netherlands over the long term, although the changed temperature in each year influenced RECpc significantly.

The energy-mix effect decreased the Dutch RECpc, although the influence was negligible. The Dutch REC is mainly concentrated on three types of energy, consisting of natural gas, electricity and heat. The other types of energy use, such as coal and LPG, are negligible in the Netherlands. Over the 2001-2015 period, the share of natural gas declined and the shares of electricity and heat increased accordingly, leading to a decentralized energy mix in the Dutch residential sector. However, natural gas remained the most important energy source, accounting for $77.17 \%$ of the total REC in the Netherlands.

Income is the only effect that increased Dutch RECpc in the research period. In detail, until 2013, the residents' income in the Netherlands had been growing; thereafter, the income began to decline, which led to a positive contribution to RECpc changes before 2013 and a negative contribution after that. As a developed country, the residents' income kept on increasing, but the increase is getting smaller. Since 2013, the income has begun to decline, which indicates a probability of the arrival of a peak and come down at a certain stage. It is predicable that in the future, due to the declining trend of income in the Netherlands, there exists the potential for continued decline in RECpc in the Netherlands.

\section{Cross-Country Comparison and Discussion}

\subsection{Cross-Country Comparison}

Despite China's high-speed growth in RECpc over the 2001-2015 period, it still lags far behind that in the Netherlands. By decomposing the RECpc changes in both China and the Netherlands from the same perspective, we could compare the effects of the four driving forces on the RECpc changes in the two countries. Table 4 shows the percentage contributions of the four driving forces.

Table 4. Cross-country comparison of decomposition results in percentage form (2001-2015).

\begin{tabular}{ccccccc}
\hline Country & Weather (\%) & Energy Mix (\%) & Energy Intensity (\%) & Income (\%) & In Total (\%) & $\begin{array}{c}\text { RECpc Change } \\
(\mathbf{k g c e} / \mathbf{p})\end{array}$ \\
\hline China & -8.17 & 0.05 & -45.93 & 154.05 & 100.00 & 157.62 \\
Netherlands & -29.55 & -0.54 & -256.99 & 187.08 & -100.00 & -199.00 \\
\hline
\end{tabular}

Data sources: CSY, CESY and PYC (2001-2016); CBS (2017a, 2017b, 2018) and KNMI, and authors' calculations.

Over the 2001-2015 period, China's RECpc increased by 157 kgce, whereas the Dutch RECpc decreased by $199 \mathrm{kgce}$. In both countries, the income effect was one of the most important contributors to the RECpc changes and the effects are both positive for RECpc increase. In China, the income effect continued to push the RECpc increase over the whole period under study, and the effect even became increasingly important. On the other hand, in the Netherlands, although the income effect increased RECpc over the research period as well, the effect was getting smaller and even became negative after 2013. To further explain the effect of income on RECpc change, we investigate income changes in both China and the Netherlands. Figure 2 describes the income per capita in both countries, using US dollars as the constant unit. Over the 2001-2015 period, China's per capita income kept increasing from 1503 to 6491 US dollars. Meanwhile, the Dutch per capita income increased from 14,109 to 20,399 US dollars in 2001-2013, reaching a turning point in 2013, followed by a continuous decline after 2013. Comparing the per capita income levels in both countries, we find that the per capita income of China as a developing country lags far behind that of the Netherlands, indicating a huge potential of per capita income increase in the coming years. In addition, there exist a large income gap in rural and urban areas and various regions due to the imbalance of regional economic development [36], which 
led to different REC level in different regions $[37,38]$. When combining the unsaturated energy demand at this stage in China, the income per capita increase will definitely lead to an RECpc increase in the future, especially in undeveloped regions in China due to residents' strong desire to improve their quality of life [39]. On the contrary, the per capita income in the Netherlands as a developed country is rather high but it has been decreasing since 2013. It is difficult to conclude that the income per capita in the Netherlands has already turned into a definite decline. Nonetheless, at least we can predict that the Dutch income per capita will not continuously increase in the coming years, which will not lead to an RECpc increase in the future.

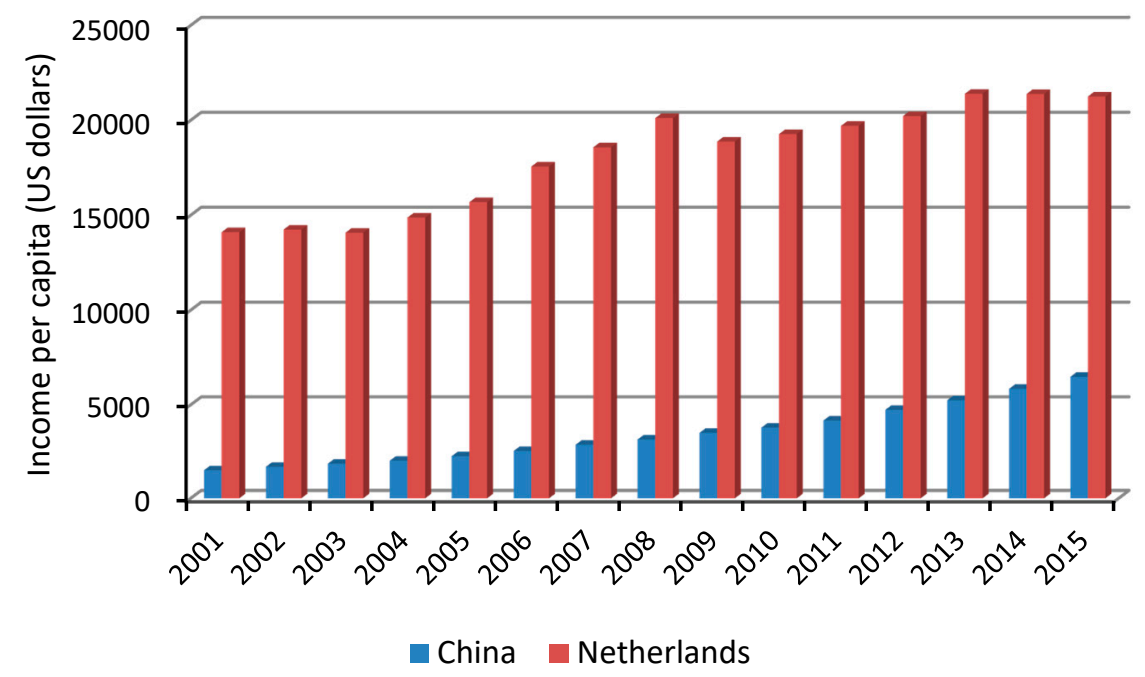

Figure 2. Comparison of income per capita in China and the Netherlands in the unit of US dollars. Data sources: CSY, CESY and PYC (2001-2013); CBS (2016), and authors' calculation.

The second driving force analyzed in this study is the energy-intensity effect. As mentioned, the energy-intensity effect is defined as REC divided by income, which plays a negative role in RECpc changes both in China and the Netherlands (see Table 3). These findings could be further explained by investigating the change processes of energy intensity in both countries (Figure 3).

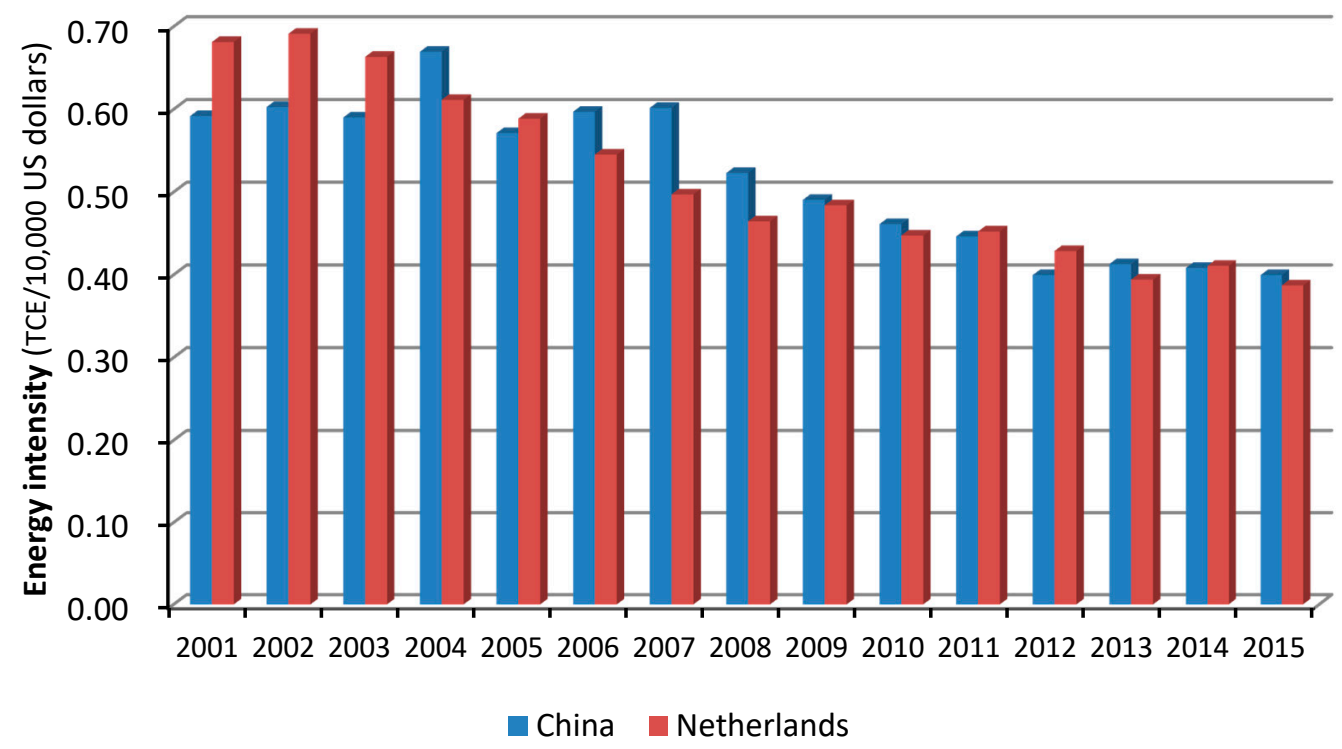

Figure 3. Comparison of energy intensity in China and the Netherlands in the unit of TCE/10,000 US dollars. Data sources: CSY, CESY and PYC (2001-2016); CBS and KNMI, and authors' calculations. 
China's energy intensity fluctuated in the first half of the research period, followed by a sharp decline after 2007 (linked with income growth), indicating an unsatisfied energy demand before 2007 and a process of gradually satisfied energy demand afterwards. However, over the whole period under study (2001-2015), China's decline of energy intensity is not as sharp as that of the Netherlands, indicating that although China's energy intensity had been significantly reduced, there is still a potential for decreasing it further in the future. In the Netherlands, the sharp decline of energy intensity played overwhelming roles in RECpc decline over the research period. Therefore, even though the income effect contributed a lot to RECpc in the Netherlands, the sharp decline of energy intensity still caused the RECpc to finally decline. In the research period, several energy efficiency policies, such as the "National Energy Efficiency Action Plan", were implemented as part of the obligation to report to the European Commission under the Energy Efficiency Directive, which led to the sharp decline of energy intensity in the Netherlands.

The increase of energy intensity in this study could be explained by the fact that people spent more of their income on REC. Hence, it is necessary to investigate the relationship between REC and income. In fact, some researchers have analyzed the economic growth and specified income effect on energy use [40-42]. Soytas and Sari examined the causality relationship between income and energy consumption in some developed countries and concluded that in Italy and Korea, the causality flowed from income to energy consumption [40]. Richmond and Kaufmann analyzed the relationship between income and energy use, pointing out that the economic development level affected their conclusion about whether there was a turning point in the relationship between income and energy use [43]. For developed countries (OECD members), there is limited support for a turning point in the relationship between income and energy use. On the other hand, for developing countries (non-OECD members), there is no turning point in the relationship between income and energy use, and the relationship is positive. The above-cited studies have given the reasons for the REC increase with the income growth in China, whereas, due to the turning point in the relationship between income and REC in the Netherlands, its REC is not necessarily influenced by the increase in income. However, when the income decreases, people are likely to reduce their unnecessary energy consumption.

The third driving force analyzed in this research is the energy-mix effect. This effect played opposite roles in the RECpc changes in the two countries (shown in Figure 4). In China, eight types of energy were consumed in the residential sector, including coal, LPG, natural gas, heat, electricity, gas, gasoline and diesel oil. Over the 2001-2015 period, the changes in the energy mix were manifested in the reduction in coal and the increase in electricity and natural gas, indicating a cleaner and more convenient energy mix. As a result of the change in the energy mix from low-efficient to high-efficient energy types, energy consumption activities became more convenient, thus increasing the REC. Compared with China's case, the Dutch energy mix had a higher concentration of natural gas. Despite some instances of transfer to electricity and heat over the 2001-2015 period, natural gas as the main residential energy type still accounted for 73\% of the Dutch REC in 2015. The government's policy of reducing dependence on natural gas pushed the diversification of the energy mix, which decreased the Dutch RECpc, due, in fact, to the habitual changes.

The weather effect is the last analyzed driving force in this study. This effect contributed to the RECpc decrease in both countries, as it influenced space heating and cooling activities in the residential sector. In China, over the 2001-2015 period, the weather effect negatively contributed to the RECpc increase before 2007, showed the characteristics of increasing RECpc in the following 2007-2012 sub-period and then continued to decrease RECpc after 2012. The possible reasons for the obvious role of the weather effect in the RECpc changes could be the high percentage of energy consumption for space heating and cooling in the total REC and the significant changes in temperature during the corresponding sub-periods [3]. Additionally, between the space heating and cooling activities in China, space heating was absolutely important because HDD accounted for $96 \%$ of the sum of HDD and CDD in 2015. In the Netherlands, owing to the relatively cool weather circumstances in the summer compared with China's weather, there was no need for space cooling activities during that season. The weather 
effect decreased RECpc over the research period due to the rise in temperature. By comparing the HDD in both countries, we conclude that the winter in both China and the Netherlands became warmer over the 2001-2015 period, leading to the corresponding RECpc changes in each country.

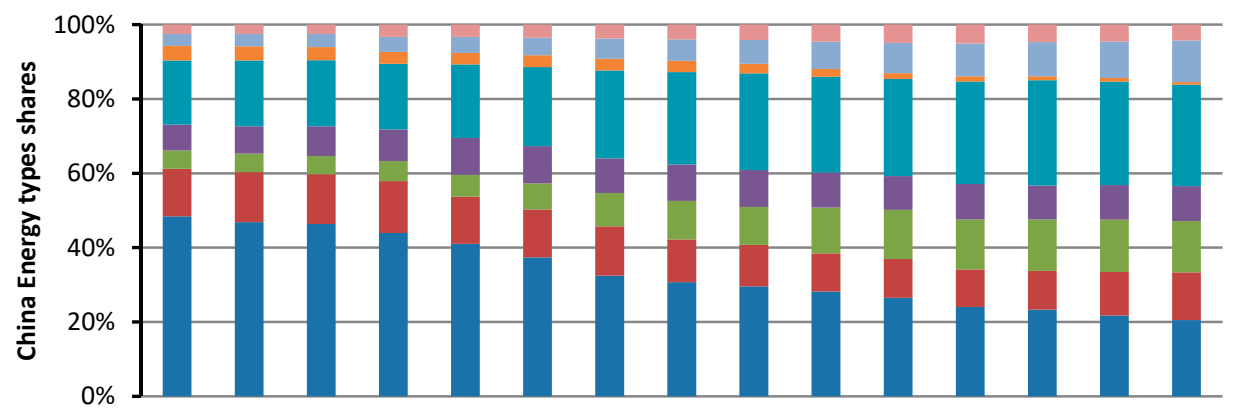

\author{
Diesel Oil \\ Gasoline \\ Gas \\ - Electricity \\ Heat \\ - Natural Gas \\ - LPG \\ - Coal
}

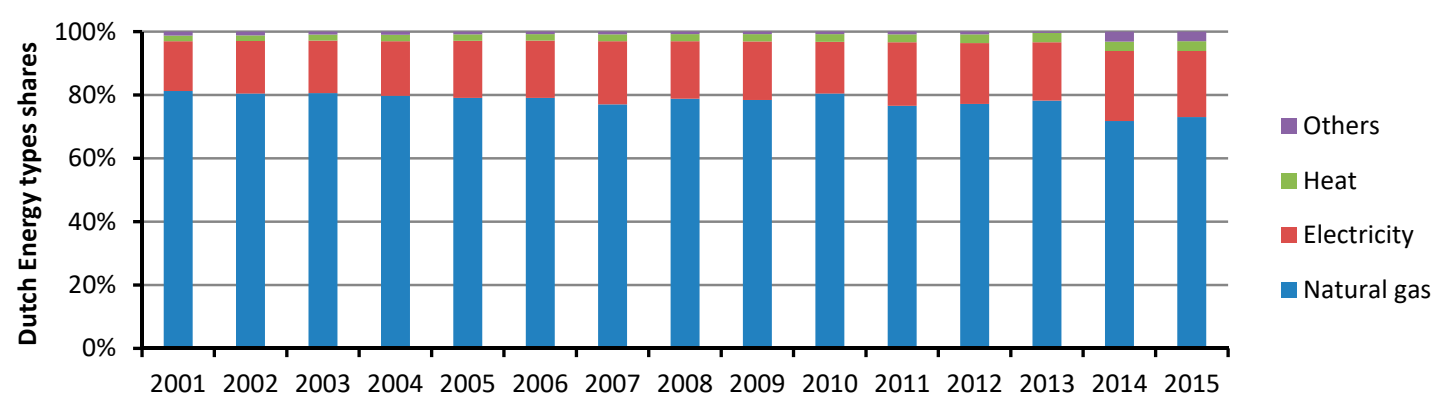

Figure 4. Comparison of energy mix in China and the Netherlands. Data sources: CESY (2001-2016); CBS and authors' calculations.

\title{
5.2. Discussion
}

Through the comparison of RECpc changes in China and the Netherlands, which are at different stages of development, we find large differences in RECpc between the two countries. It may be claimed that China has the highest energy consumption in the world, but we argue that Chinese residents had very low per capita energy use over the past decade, based on our comparison. Despite experiencing a rapid rise over the past decade, China's RECpc remained less than a third of the Netherlands' in 2015. After investigating the reasons, we attribute the low RECpc in China to the low income levels and the geographic concentration of residential areas. In 2015, the Chinese per capita income was only around $20 \%$ of that in the Netherlands. Additionally, compared with the more geographically scattered residential areas in the Netherlands, China had a higher population density, especially in urban areas. For example, most Chinese residents lived in apartments, whereas most Dutch residents dwelled in houses, leading to the difference in living space per capita in the two countries. Based on our analysis in this section, China's RECpc continued to increase over the 2001-2015 period, while the Dutch RECpc declined in the process of fluctuation, indicating a huge growth potential of RECpc in China and a saturated RECpc in the Netherlands. With their income growth in the coming years, Chinese residents will spend more on energy, leading to a continuous RECpc growth; at the same time, they will spend more on larger accommodations, leading to higher RECpc indirectly [44].

Energy intensity as a driving force played negative roles in RECpc increase in developing and developed countries. In developing countries, the income growth will definitely lead to an REC increase, showing different driving effects at different phases [43]. In China's case, at the early stage, because its residents' basic REC demand had not been met yet, more of their income was spent on REC, leading to the increase in energy intensity. At the following stage, the residents' basic REC demand had been gradually met, making them spend less of their income on REC, which led to the decline in energy intensity after 2007. However, in the developed countries, owing to the saturation of the REC demand, the impact of income on REC has become negligible. In the case of the Netherlands, due to the saturation of REC demand and increased income, energy intensity declined over the research 
period. Because the energy intensity in China remains higher than that in the Netherlands, it is highly probable that this declining trend will be maintained in the future, which will restrain the RECpc increase to some extent.

Weather has an important effect on RECpc changes by influencing both heating and cooling energy consumptions, which is a novel finding of this study. In the case of the two countries, the weather effect played negative roles in RECpc changes, owing to the warmer winter or the cooler summer. The relatively warmer weather in the winter decreased RECpc in both China and the Netherlands. However, these changes have nothing to do with the difference between developed and developing countries. In addition, technological innovation and institutional reforms will definitely lead to the development of energy efficient appliances and energy-saving behaviors [45,46], but the unmet energy demand gap will remain the core driving force for RECpc growth in China.

\section{Conclusions and Policy Implications}

\subsection{Conclusion}

In this study, we conducted a cross-country comparison of the RECpc between the Netherlands, a developed (OECD member) country, and China, a developing (non-OECD member) country. We observed that the RECpc in China lags far behind that in the Netherlands, despite China's increasing growth over the last decade. By further decomposing the RECpc changes in both countries based on the same LMDI method, we investigated and compared the driving forces behind the RECpc changes. We decomposed the changes into four effects: weather, energy mix, energy intensity and income. Based on our decomposition analysis of the driving forces behind the RECpc changes in a developed and a developing country, we obtained the following findings.

An increasing RECpc in China's case was observed due to the continuous income growth and the more convenient energy mix. In the Netherlands' case, the sharply declining energy intensity, the relatively warmer winters and the more dispersed energy mix together pushed the decline in RECpc. The different stages of economic development led to different characteristics of REC in the two countries. Because the RECpc gap still exists between the two countries, it is not difficult to predict that although energy efficiency will definitely be improved, the RECpc in China will still increase in the coming years until the residents' energy demand is met fully, should the economic growth maintain its current trend. In contrast, due to the relatively high RECpc level in the Netherlands, it will possibly decline in the future, with energy efficiency improvement and energy-saving behaviour spread throughout the country.

\subsection{Policy Implications}

By comparing the RECpc and its driving forces in China and the Netherlands as typical examples, we obtain implications about the law of REC in developing and developed countries. The large gap in income per capita causes the large gap in RECpc between developing and developed countries. Although in recent years the high-speed income growth as a result of the rapid economic progress in developing countries has narrowed the RECpc gap, it remains large. Owing to the low income in developing countries, the REC demand has not been fully satisfied yet, but the increasing income in the residential sector definitely leads to REC growth. It is not difficult to predict that as the residents' energy demands are met, the speed of the REC growth will slow down. On the other hand, in developed countries, the saturation of the energy demand leads to RECpc stability despite the income increase. Nonetheless, we may predict that RECpc would decline under the two circumstances, including cutting unnecessary REC when income declines and improving energy efficiency, which is currently occurring. We argue that the dramatic RECpc increase in developing countries is in line with the objective laws of RECpc development, which will slow down and reach a turning point, owing to the saturation of energy demand and further improvement in energy efficiency. 
Owing to the different development stages and their corresponding characteristics in RECpc in developed and developing countries, different energy policies should be adopted according to the development stages. For developed countries, energy policy should be oriented towards improving residential energy efficiency by encouraging appliances' eco-innovation and motivating energy saving behavior. For instance, energy prices could be raised to reduce the unnecessary REC. In addition, efficient appliances should be subsidized by the government to encourage residents to buy energy efficient appliances and motivating eco-innovation indirectly. For developing countries, moderate growth of RECpc should be encouraged as long as the basic energy demand has not been met yet, especially in rural areas [47-49]. In addition, there exists a large gap in income and an unbalanced development in urban and rural areas in developing countries [50-52], which lead to different RECpc in different groups and areas [53-55]. Therefore, varied pricing for energy policy should be adopted in developing countries, which would encourage low-income residents to use more REC and in the meantime avoid excessive REC in high-income groups. Additionally, the weather effect should be considered in pricing for heating systems. In the case of China, even though energy consumption for heating is influenced significantly by the weather [3], because central heating is the main form of heating in the residential sector, the price of central heating is constant in a certain period. The residents have no incentives to preserve energy for heating in relative warm winters due to the constant expenditure they spent on heating each winter. Therefore, it is highly recommended to adapt the price of heating based on weather conditions.

Author Contributions: Conceptualization, H.N.; Data curation, V.V.; Formal analysis, H.N.; Investigation, V.V.; Methodology, H.N.; Project administration, R.K.; Supervision, R.K.; Validation, R.K.; Visualization, V.V.; Writing —original draft, H.N.; Writing — review \& editing, V.V. All authors have read and agreed to the published version of the manuscript.

Funding: This research was funded by Foundation for the Humanities and Social sciences of the Ministry of Education of China, grant number 20YJC790101; and National Natural Sciences Foundation of China, grant number 71503026 and 71690245 . The APC was funded by National Natural Sciences Foundation of China.

Conflicts of Interest: The authors declare no conflict of interest. The funders had no role in the design of the study; in the collection, analyses, or interpretation of data; in the writing of the manuscript, or in the decision to publish the results.

\section{References}

1. Department of Energy Statistics of National Bureau of Statistic of China (DESNBS). China Energy Statistical Yearbooks; China Statistics Press: Beijing, China, 2009-2016.

2. Central Agency for Statistics (CBS). Bevolking en bevolkingsontwikkeling, per maand, kwartaal en jaar, 2001-2015. Available online: http://statline.cbs.nl/Statweb/publication/?DM=SLNL\&PA=37943ned\& D1=7\&D2=118,135,152,169,186,203,220,237,254,271,288,305\&HDR=T\&STB=G1\&VW=T (accessed on 28 December 2017).

3. Nie, H.; Kemp, R.; Xu, J.; Vasseur, V.; Fan, Y. Drivers of urban and rural residential energy consumption in China from the perspectives of climate and economic effects. J. Clean. Prod. 2018, 172, 2954-2963. [CrossRef]

4. Achão, C.; Schaeffer, R. Decomposition analysis of the variations in residential electricity consumption in Brazil for the 1980-2007 period: Measuring the activity, intensity and structure effects. Energy Policy 2009, 37, 5208-5220. [CrossRef]

5. Hojjati, B.; Wade, S.H. U.S. household energy consumption and intensity trend: A decomposition approach. Energy Policy 2012, 48, 304-314. [CrossRef]

6. Yao, C.; Chen, C.; Li, M. Analysis of rural residential energy consumption and corresponding carbon emissions in China. Energy Policy 2012, 41, 445-450. [CrossRef]

7. Shorrock, L.D. Identifying the individual components of United Kingdom domestic sector carbon emission changes between 1990 and 2000. Energy Policy 2000, 28, 193-200. [CrossRef]

8. Greening, L.A.; Ting, M.; Krackler, T.J. Effects of changes in residential end-uses and behavior on aggregate carbon intensity: Comparison of 10 OECD countries for the period 1970 through 1993. Energy Econ. 2001, 23, 153-178. [CrossRef] 
9. Unander, F.; Ettestol, I.; Ting, M.; Schipper, L. Residential energy use: An international perspective on long-term trends in Denmark, Norway and Sweden. Energy Policy 2012, 32, 1395-1404. [CrossRef]

10. Rogan, F.; Cahill, C.J.; Gallachoir, B.P.O. Decomposition analysis of gas consumption in the residential sector in Ireland. Energy Policy 2012, 42, 19-36. [CrossRef]

11. Das, A.; Paul, S.K. CO 2 emissions from household consumption in India between 1993-94 and 2006-07: A decomposition analysis. Energy Econ. 2014, 41, 90-105. [CrossRef]

12. Shaikh, F.; Ji, Q.; Fan, Y. The diagnosis of an electricity crisis and alternative energy development in Pakistan. Renewable and Sustainable. Energy Rev. 2015, 52, 1172-1185.

13. Zha, D.; Zhou, D.; Zhou, P. Driving forces of residential $\mathrm{CO}_{2}$ emissions in urban and rural China: An index decomposition analysis. Energy Policy 2010, 38, 3377-3383.

14. Zhang, M.; Guo, F. Analysis of rural residential commercial energy consumption in China. Energy 2013, 52, 222-229. [CrossRef]

15. Zhang, M.; Song, Y.; Li, P.; Li, H. Study on affecting factors of residential energy consumption in urban and rural Jiangsu. Renew. Sustain. Energy Rev. 2016, 53, 330-337. [CrossRef]

16. Zhao, X.; Li, N.; Ma, C. Residential energy consumption in urban China: A decomposition analysis. Energy Policy 2012, 41, 644-653. [CrossRef]

17. Nie, H.; Kemp, R. Index decomposition analysis of residential energy consumption in China: 2002-2010. Appl. Energy 2014, 121, 10-19. [CrossRef]

18. Liu, Z.; Zhao, T. Contribution of price/expenditure factors of residential energy consumption in China from 1993 to 2011: A decomposition analysis. Energy Convers. Manag. 2015, 98, 401-410. [CrossRef]

19. Ang, B.W. Decomposition analysis for policymaking in energy: Which is the preferred method? Energy Policy 2004, 32, 1131-1139. [CrossRef]

20. Xu, J.; Fan, Y.; Yu, S. Energy conservation and $\mathrm{CO}_{2}$ Emission reduction in China's 11th Five-Year Plan: A performance evaluation. Energy Econ. 2014, 46, 348-359. [CrossRef]

21. Ang, B.W. LMDI decomposition approach: A guide for implementation. Energy Policy 2015, 86, $233-238$. [CrossRef]

22. Ang, B.W.; Liu, F.L. A new energy decomposition method: Perfect in decomposition and consistent in aggregation. Energy 2001, 26, 537-548. [CrossRef]

23. Ang, B.W. The LMDI approach to decomposition analysis: A practice guide. Energy Policy 2005, 33, 867-871. [CrossRef]

24. Chung, W.; Kam, M.S.; Ip, C.Y. A study of residential energy use in Hong Kong by decomposition analysis, 1990-2007. Appl. Energy 2011, 88, 5180-5187. [CrossRef]

25. National Bureau of Statistics of China (NBS). China Statistical Yearbooks; China Statistics Press: Beijing, China, 2002-2016.

26. Department of Industry and Transport Statistics of National Bureau of Statistic of China(DITSNBS); Energy Bureau of National Development and Reform Commission of China(EBNDRC). China Energy Statistical Yearbook; China Statistics Press: Beijing, China, 2003-2007.

27. Department of Energy Statistics of National Bureau of Statistic of China (DESNBS); Department of General Affairs of National Energy Administration (DGANEA). China Energy Statistical Yearbook; China Statistics Press: Beijing, China, 2008.

28. CBS. Rijk, Uitgaven En Ontvangsten Begrotings Hoof Dstukken, 2001-2015. Available online: http://statline.cbs.nl/Statweb/publication/?DM=SLNL\&PA=60050\&D1=0-1\&D2=0\&D3=9-14\&HDR= G2,T\&STB=G1\&VW=T (accessed on 30 June 2017).

29. CBS. Energie, Verbruik En Producentenprijs Naar Energiedrager, 2001-2015. Available online: http://statline.cbs.nl/Statweb/publication/?DM=SLNL\&PA=80324ned\&D1=2-3\&D2=a\&D3=118,135, $152,169,186,203,220,237,254,271,288,305 \& H D R=G 2 \& S T B=T, G 1 \& V W=T$ (accessed on 10 January 2018).

30. Royal Netherlands Meteorological Institute (KNMI). Weerstatistieken De Bilt; Maandgemiddelde temperaturen. 2018. Available online: https://weerstatistieken.nl/de-bilt/2017/april (accessed on 10 January 2018).

31. OECD. Purchasing Power Parities (PPP) (indicator). 2018. Available online: https://stats.oecd.org/ (accessed on 30 June 2018).

32. OECD/Eurostat. Eurostat-OECD Methodological Manual on Purchasing Power Parities; OECD Publishing: Paris, France, 2012. [CrossRef] 
33. APERC. Energy Efficiency Indicators—A Study of Energy Efficiency Indicators in Apec Economies; APERC: Tokyo, Japan, 2001.

34. Guo, J.; Wu, S.; Hu, J.; Wei, C. Modeling energy intensity of residential space heating. Energy Effic. 2019, 12, 921-931. [CrossRef]

35. Fan, Y.; Xia, Y. Exploring energy consumption and demand in China. Energy 2012, 40, 23-30. [CrossRef]

36. Molero-Simarro, R. Inequality in China revisited. The effect of functional distribution of income on urban top incomes, the urban-rural gap and the Gini index, 1978-2015. China Econ. Rev. 2017, 42, 101-117. [CrossRef]

37. He, Z.; Xu, S.; Shen, W.; Long, R.; Chen, H. Impact of urbanization on energy related $\mathrm{CO}_{2}$ emission at different development levels: Regional difference in China based on panel estimation. J. Clean. Prod. 2017, 140, 1719-1730. [CrossRef]

38. Miao, L. Examining the impact factors of urban residential energy consumption and $\mathrm{CO}_{2}$ emissions in China-Evidence from city-level data. Ecol. Indic. 2017, 73, 29-37. [CrossRef]

39. Defila, R.; Giulio, A.D.; Schweizer, C.R. Two souls are dwelling in my breast: Uncovering how individuals in their dual role as consumer-citizen perceive future energy policies. Energy Res. Soc. Sci. 2018, 35, 152-162. [CrossRef]

40. Soytas, U.; Sari, R. Energy consumption and GDP: Causality relationship in G-7 countries and emerging markets. Energy Econ. 2003, 25, 33-37. [CrossRef]

41. Wang, W.; Li, M.; Zhang, M. Study on the changes of the decoupling indicator between energy-related $\mathrm{CO}_{2}$ emission and GDP in China. Energy 2017, 128, 11-18. [CrossRef]

42. Zhang, M.; Bai, C. Exploring the influencing factors and decoupling state of residential energy consumption in Shandong. J. Clean. Prod. 2018, 194, 253-262. [CrossRef]

43. Richmond, A.K.; Kaufmann, R.K. Is there a turning point in the relationship between income and energy use and/or carbon emissions? Ecol. Econ. 2006, 56, 176-189. [CrossRef]

44. Guo, X.; Zhu, L.; Fan, Y.; Xie, B. Evaluation of potential reductions in carbon emissions in Chinese provinces based on environmental DEA. Energy Policy 2011, 39, 2352-2360. [CrossRef]

45. Mori, A. Socio-technical and political economy perspectives in the Chinese energy transition. Energy Res. Soc. Sci. 2018, 35, 28-36. [CrossRef]

46. Hasanov, M.; Zuidema, C. The transformative power of self-organization: Towards a conceptual framework for understanding local energy initiatives in The Netherlands. Energy Res. Soc. Sci. 2018, 37, 85-93. [CrossRef]

47. Wang, R.; Jiang, Z. Energy consumption in China's rural areas: A study based on the village energy survey. J. Clean. Prod. 2017, 143, 452-461. [CrossRef]

48. Wang, X.; Li, K.; Li, H.; Bai, D.; Liu, J. Research on China's rural household energy consumption-Household investigation of typical counties in 8 economic zones. Renew. Sustain. Energy Rev. 2017, 68, $28-32$.

49. Ding, Z.; Wang, G.; Liu, Z.; Long, R. Research on differences in the factors influencing the energy-saving behavior of urban and rural residents in China-A case study of Jiangsu Province. Energy Policy 2017, 100, 252-259. [CrossRef]

50. Li, Y.; Wang, X.; Zhu, Q.; Zhao, H. Assessing the spatial and temporal differences in the impacts of factor allocation and urbanization on urban-Rural income disparity in China, 2004-2010. Habitat Int. 2014, 42, 76-82. [CrossRef]

51. Su, C.; Liu, T.; Chang, H.; Jiang, X. Is urbanization narrowing the urban-Rural income gap? A cross-regional study of China. Habitat Int. 2015, 48, 79-86. [CrossRef]

52. Li, Y.; Dacosta, M.N. Transportation and income inequality in China: 1978-2007. Transp. Res. Part A 2013, 55, 56-71. [CrossRef]

53. Wang, Y.; Li, L.; Kubota, J.; Han, R.; Zhu, X.; Lu, G. Does urbanization lead to more carbon emission? Evidence from a panel of BRICS countries. Appl. Energy 2016, 168, 375-380. [CrossRef]

54. Wang, Q.; Wu, S.; Zeng, Y.; Wu, B. Exploring the relationship between urbanization, energy consumption, and $\mathrm{CO}_{2}$ emissions in different provinces of China. Renew. Sustain. Energy Rev. 2016, 54, 1563-1579. [CrossRef]

55. Fan, J.; Zhang, Y.; Wang, B. The impact of urbanization on residential energy consumption in China: An aggregated and disaggregated analysis. Renew. Sustain. Energy Rev. 2017, 75, 220-233. [CrossRef]

(C) 2020 by the authors. Licensee MDPI, Basel, Switzerland. This article is an open access article distributed under the terms and conditions of the Creative Commons Attribution (CC BY) license (http://creativecommons.org/licenses/by/4.0/). 